\title{
BOW-AND-ARROW TECHNOLOGY: MAPPING HUMAN COGNITION AND PERHAPS LANGUAGE EVOLUTION
}

\author{
ALEXANDRA REGINA KRATSCHMER
}

Department of Aesthetics and Communication, Aarhus University, Jens Chr. Skous Vej 4, DK-8000 Aarhus, Denmark

\author{
MIRIAM NOËL HAIDLE
}

Research center "The Role of Culture in Early Expansions of Humans" of the Heidelberg Academy of Sciences, Senckenberg Research Institute, Senckenberganlage 25, D-60325 Frankfurt/M., Germany

MARLIZE LOMBARD

Department of Anthropology and Development Studies, University of Johannesburg, PO Box 524, Auckland Park, 2006, South Africa

Here we highlight the potential relationship between the cognitive underpinnings of complementary tool technology (e.g., the bow and arrow) with its elaborated action structure and those of modern linguistic structures referring to action planning, characterized by recursive and embedded patterns and concepts of time (past and future).We suggest that, whereas complementary technologies neither require nor imply 'modern' language, modern language syntax and semantics exploit some of the cognitive functions necessary for complementary tool use, i.e., syllogistic reasoning. Neurological experiments show a shared neural substrate for prehistoric stone tool-making (manual praxis) and language and argue for co-evolution of the two (Uomini \& Meyer 2013). Using dated archaeological material to interpret cognitive aptitude in certain spatiotemporal contexts, we can estimate a minimum age for levels of cognitive complexity in human thinking, perhaps indicating functions performed by modern language.

Human cognitive evolution can be traced by coding the structure of tool behavior (conception, manufacture and use) in 'cognigrams' (Haidle 2012). Problem-solution distances inherent in tool behaviors show an expansion of cultural capacities in human evolution. Complementary cultural capacities refer to a set of cultural modules that act as an entity with interdependent parts, a set, and they are expressed in complementary tool sets like bow-and-arrow. The earliest current evidence stems from South African stone artefacts used as arrow tips dating to $65 \mathrm{ka}$. 
The cognigrams of complementary tool sets (Lombard \& Haidle 2012) resemble a whole story with several agents/objects with varying causal relationships to be handled over a considerable time span. They potentially reflect the cognitive capacities central to shaping the syntactic and semantic landscape of modern language sentences and texts. For example, composite capacities show structures with two or more lines of action leading to a joint end which can be reached by trial-and-error, but complementary capacities require syllogisms: "A bow can enhance projectiles with character $\mathrm{X}$. An arrow with character $\mathrm{Y}$ can kill the prey. Conclusion: an arrow needs character $\mathrm{X}$ and $\mathrm{Y}$ and has to be enhanced by a bow to kill the prey." Without formal reasoning and acting you cannot make the complementary tool sets work. An important part of modern language products refers to the planning, negotiation or post hoc explanation (goals and sub-goals, motives, excuses) of human action. Whereas the concrete verbalizations vary in surface complexity, the underlying semantics can always be traced to the same reasoning patterns, syllogistic in nature (Kratschmer 2005). Complementary capacities do not presuppose the existence of language. If we can imagine tool manufacturing without the use of symbolic language, we might even suggest that syllogistic reasoning - in contrast to its definition as cognitive operations executed on sentences and hence language - is not dependent on propositional thinking in a strictly linguistic sense.

Where and when humans first used 'modern' language remains elusive. Here we propose that, based on the cognitive capacities reflected in bow-andarrow technology (modular use of units to produce a multitude of potentially different processes, episodic structuring of sub-goals, recognition of formal specificities of sub-goals, etc.), a number of key elements of modern grammarlike structure are evident in the archaeological record of southern Africa by at least $65 \mathrm{ka}$.

\section{References}

Haidle, M. N. (2012). How to think tools? A comparison of cognitive aspects in tool behavior of animals and during human evolution. Cognitive perspectives in tool behaviour, Vol. 1. http://tobias-lib.uni-tuebingen. de/frontdoor.php?source_opus=6014

Kratschmer, A. (2005). Erklärungsstragegien, semantische Felder und Makrostrukturen. Eine Fallstudie zur Architektur von explikativen Texten. Aarhus: Aarhus Universitetsforlag.

Lombard, M. \& Haidle, M.N. (2012). Thinking a bow-and-arrow set: cognitive implications of Middle Stone Age bow and stone-tipped arrow technology. Cambridge Archaeological Journal 22:2, 237-64.

Uomini, N. T. \& Meyer G. F. (2013). Shared brain lateralization patterns in language and acheulean stone tool production: a functional transcranial doppler ultrasound study. PLoS One 8:8, e72693. 